\title{
WALLERSTEIN, ARRIGHI E AMIN: 0 IMPERIALISMO NO CAPITALISMO FORDISTA
}

\section{Luiz Felipe Brandão Osorio ${ }^{1}$}

\section{Introdução: 0 Capitalismo Fordista}

Sempre atual e presente, o imperialismo nunca deixou de rondar as relações internacionais. Ao contrário, mesmo quando tido como superado, ele moldou os rumos mundiais, acompanhando a toada de transformações do capitalismo. Agora, em meio ao jubileu centenário dos primeiros debates, o imperialismo retoma a carga em plena potência. Após um curto interregno de ilusória prosperidade no limiar da transição entre séculos, o tão propalado termo volta à boca e aos ouvidos dos operadores e dos estudiosos das relações internacionais. Em muito o protagonismo hodierno deve-se aos rumos práticos e teóricos que impactaram o estudo do sistema de Estados. Refletir sobre esse vocábulo não é um exercício simples. Ele traduziu os rumos do desenvolvimento do capitalismo desde o século XIX, tendo oscilado como nenhum outro na trajetória sistêmica.

Imperialismo e relações internacionais ganham um conteúdo específico justamente na consolidação do capitalismo enquanto modo de produção mundial predominante. Os temas se inter-relacionam diretamente. Por isso, fazer a crítica de um significa tocar a todos em maior ou menor medida. Nesse sentido, muitos autores se propuseram a fazer a crítica ao capitalismo internacional. Poucos lograram êxito em resistir ao tempo e às dificuldades, sendo reconhecidos até hoje por várias gerações, Esses merecem um destaque especial. Ainda que situados em seu tempo histórico, foram pensadores que não se vinculavam a um espaço geográfico nacional, sendo considerados intelectuais do mundo. Ademais, não bastasse sua

I Professor Adjunto de Direito e Relações Internacionais na Universidade Federal Rural do Rio de Janeiro (UFRRJ). 
potência nas ideias, eles também ganharam notoriedade pelo engajamento político e militante, sempre na defesa intransigente da periferia e contra as desigualdades do desenvolvimento. Nesse diapasão, vale a pena discutir Immanuel Wallerstein, Giovanni Arrighi e Samir Amin.

Os três notabilizaram-se pela crítica atroz ao liberalismo e aos rumos do capitalismo mundial. Como viveram por muitos anos, atravessaram transformações importantes no sistema internacional. E se tornaram autores incontornáveis para os estudos críticos das relações internacionais. Ainda que seja para refutar suas premissas, é necessário lê-los e entendêlos. Suas perspectivas mais se aproximam entre si do que se afastam, apesar das dissonâncias marcadas. A razão dos muitos pontos de convergência deve-se, dentre outros fatores, ao momento histórico do capitalismo em que construíram suas posições. Como filhos de seu contexto, eles desenvolveram suas ideias a partir de um ponto da trajetória do capitalismo que em muito explica suas premissas e suas posturas: o do capitalismo fordista.

O sentido aqui atribuído ao termo caracteriza um padrão de desenvolvimento das relações de produção capitalistas. Apesar da origem do termo designar a homenagem a Henry Ford que inseriu pioneiramente a esteira rolante na montagem de automóveis, o fordismo aqui discutido toca o sentido dado pela teoria materialista do Estado e pela escola regulacionista francesa, e não se confunde com a semântica dada por Gramsci (2008). O fordismo não está relacionado às ideias de organização da produção industrial retiradas originariamente de Frederick Taylor, mas, sim, abarca um padrão de desenvolvimento, composto pelos regime de acumulação e modo de regulação correspondentes a um período histórico do desenvolvimento capitalista específica, impulsionado pela crise estrutural de i929 e pela Segunda Guerra Mundial (Jessop I99I). O pós-I945 foi costurado sob um modelo embasado em dois alicerces: o regime de acumulação interno, nacional, estruturado nos moldes do que se conhece como o capitalismo industrial; e o modo de regulação estatal-intervencionista (keynesiano ou de bem-estar social), com disposições legais e burocráticas sobre a vivência social, na busca por bemestar, consumo e crescimento.

O novo ciclo do capitalismo que se inaugura após a crise econômica de 1929 e a decorrente Segunda Guerra Mundial e vai até a debacle nos anos I970 possui contextos históricos e teóricos muito particulares, ocasionando um ínterim de excepcional e pontual estabilidade relativa na trajetória do centro de acumulação do sistema capitalista (o que não chegou à periferia). O momento de recuperação econômica e de composição política em torno da socialdemocracia como armas de contenção do alastramento da vitória da Revolução Russa mudaram a face do padrão de desenvolvimento do 
capitalismo. Inquestionavelmente conciliou-se um cenário de crescimento econômico em escala mundial acompanhado pelo incremento substancial dos índices sociais. A emergência dos Estados Unidos, enquanto potência hegemônica, e a ascensão da União Soviética que simbolizava a chegada da esquerda ao poder (assim como o eurocomunismo), bem como o espraiamento das relações capitalistas pelos quadrantes do mapa-múndi, conferiram ao capitalismo uma nova face.

Nesse cenário moldam-se as lutas operárias e a reorganização das estruturas capitalistas. Das concepções fortemente liberalizantes irradiadas anteriormente partiu-se para: concessões ao trabalho, mediante expansão de direitos; o ancoramento das relações de produção em bases nacionais-estatais, com fomento à demanda agregada, crescimento e consumo de massa; e a regulação do fluxo de capitais pelo mundo via configuração formal e informal da hegemonia estadunidense. O capitalismo liberal migrou para uma solução de compromisso em torno do capitalismo fordista, adjetivo que qualifica o que podemos chamar de segundo debate ${ }^{2}$.

Nessa dinâmica, com as esquerdas no poder, quer pela via revolucionária, quer pelo compromisso socialdemocrata, e com as relações de produção alastrando-se por todos os quadrantes do globo, teoricamente, emerge um cenário inédito. $\mathrm{O}$ marxismo como um todo inaugura a tradição ocidental (e por consequência a oriental) ${ }^{3}$ e, gradativamente, as reflexões sobre imperialismo expandem-se, esgarçando os limites do continente europeu e abarcando outras regiões pelo mundo, estabelecendo uma dualidade: de concepções centrais, que negam e reafirmam o imperialismo, adaptando-o às novas condicionantes; e de visões voltadas à periferia, as quais contribuem e inovam substancialmente ao debate, logo, sendo objeto de uma investigação mais detida. Nesse diapasão, estão presentes a corrente do capital monopolista (Baran e Sweezy), os teóricos marxistas da dependência (Frank, Dos Santos, Bambirra e Marini) e os terceiro-mundistas ${ }^{4}$ (teóricos do sistema-mundo e das trocas desiguais, como Wallerstein, Arrighi e Amin). Os últimos serão objeto de análise deste artigo.

2 O debate pioneiro do imperialismo ocorreu em um contexto histórico e teórico muito específico que vai do quartel final do século XIX até aproximadamente a Segunda Guerra Mundial e é o pioneiro e mais conhecido sobre as compreensões do imperialismo (Osorio 20I8).

3 Anderson (2004) e Losurdo (2018).

4 Sem qualquer conotação pejorativa, sem pretender se rogar na posição de superioridade da arrogância do dito Primeiro Mundo, ao contrário, destacando o caráter autóctone e original das reflexões, são referidos nesse trabalho como terceiro-mundistas aqueles que se voltam à ênfase às trocas desiguais e ao sistema-mundo, conforme classifica boa parte da doutrina oriundo os países centrais. Para mais ver Brewer (I990), Barone (I990), Carnoy (I994), Nogueira e Messari (2005), Noonan (20I7). 
O conceito de imperialismo em si, muito identificado com os pioneiros, com o marxismo tradicional e seu contexto histórico é revisado e, inevitavelmente, eclipsado. Uma vez que era tido como intimamente ligado à base econômica, à estrutura capitalista, e as reflexões marxistas direcionavam-se para a superestrutura (aspectos filosóficos, políticos, jurídicos e ideológicos), bem como o contexto de crise de acumulação, competição interestatal e guerras sistêmicas havia se dissipado, o conceito de imperialismo foi diluído (quando não pulverizado) em outros elementos aparentemente mais amplos. No centro, ou se rechaçou ou se atualizou a noção de imperialismo. Na periferia, as contribuições significativas vieram com as aplicações dos ensinamentos dos pioneiros à realidade local. O que aparece de novidade aqui é o redirecionamento do foco para a periferia e seus problemas estruturais, os quais são radicalmente distintos daqueles do centro capitalista. Fica, assim, compreensível, o imperialismo não constituir o ponto nevrálgico das análises. Ele acaba sendo levado de roldão em meio à premência da ênfase a outros aspectos, de teorização ainda recente no panorama mundial, como a dominação do centro à periferia e as relações de dependência desta ao capitalismo central pelo intercâmbio comercial, transferência de valor ou pelas trocas desiguais, bem como pela divisão internacional do trabalho e pelo sistema-mundo.

A discrepância entre centro e periferia torna-se incontornável não apenas pela expansão do capitalismo no mundo, mas pela relativa prosperidade que o centro gozara em relação às mazelas que assombravam as regiões marginais. Logo, é nesse panorama que a novidade reluz. O engajamento e as lutas revolucionários foram fermentos importantes na construção de um pensamento crítico autóctone. O europeísmo5 ${ }^{5}$, predominante nas visões pioneiras, requeria ser rompido, uma vez que havia demandas específicas das periferias que se colocavam como prementes, não sendo mais o capitalismo e seus desdobramentos exclusividade de uma região. É a partir da origem europeia que o imperialismo se torna assunto dos intelectuais das mais diversas nacionalidades nos quatro cantos do mundo.

A unidade de análise não é a formação social nacional e a correlação de classes, mas o sistema mundial, como um conjunto, tendo áreas geográficas distintas, e sendo partes os Estados desse todo. O imperialismo deixa de

5 Não que se afirme aqui que os autores pioneiros eram propositalmente excludentes. Por exemplo, o próprio Lênin, com mais ênfase, já denunciara a desigualdade existente. O viés europeísta foi natural daquele ínterim e inerente aos limites do capitalismo à época. O adjetivo em questão aborda a inevitável centralidade do pensamento europeu sobre o imperialismo naquele momento, ainda restrito aos ciclos políticos daquele continente. Ainda assim, esse traço do imperialismo pioneiro foi alvo de críticas, como as de Amin (I977a). 
ser apontado como consequência da expansão e do desenvolvimento do capitalismo, como o era anteriormente, para ser lido como elemento das relações de exploração dos países avançados no tocante aos atrasados. É um desígnio muito mais externo ao capitalismo e ao Estado do que próprio da dinâmica político-econômica.

O capitalismo não é definido por uma determinada relação de classes, mas pela produção por lucros, em um sistema mundial de intercâmbio e pela exploração de umas áreas pelas outras. As formas de exploração ocorrem por três vias, basicamente: controle monopolístico do comércio, extração do maisvalor da periferia para o centro e mediante trocas desiguais. Nessa dinâmica, a acumulação de capital não é uma precondição para avanços qualitativos nos níveis e métodos de produção, mas é uma redefinição de magnitude fixa de recursos da periferia para o centro. O sistema mundial não é o do século XIX, a historicidade aqui é outra. Ele nasce no século XVI, em uma lógica relativamente estática de exploração. Porque o capitalismo é inerentemente incapacitado para gerar a prosperidade mundial que ele precisa ser superado.

$\mathrm{Na}$ linha do debate fordista, muitos colocariam Wallerstein, Arrighi e Amin junto com os teóricos marxistas da dependência em uma mesma vertente, chamada por muitos de terceiro-mundista. Principalmente, Wallerstein e Amin são frequentemente colocados sob um mesmo rótulo, como membros da teoria da dependência, como fazem Carnoy (I994) e Barone (I985). Brewer (I990) ainda inclui Arrighi nessa vertente e segrega as trocas desiguais de Emmanuel, em relação ao que chama teóricos da dependência. Noonan (20I7) também os unifica em um mesmo grupo, chamando-os de neomarxistas. Já Martins (2OII) os aparta, colocando Amin como um socialista neodesenvolvimentista e Wallerstein e Arrighi como teóricos do sistema mundial. Nogueira e Messari (2005) atribuem a Amin uma perspectiva mais nacionalista dentro das vertentes teóricas da dependência e diferenciam Wallerstein dele em função do estruturalismo marxista do estadunidense. Em que pesem algumas similitudes dos aportes teóricos, há importantes divergências, logo, é imperioso separar suas ideias, conferindo a cada um a centralidade de suas contribuições. Por outro lado, não seria exagero afirmar que se trata de um conjunto sistema-mundo, dentro do qual há um vetor que se especializa nas trocas desiguais. Logo, a diferença mais gritante está na amplitude dos nortes analíticos. Assim, serão mencionadas a lente mais ampla, a das teorias do sistema-mundo, e a mais específica, a das trocas desiguais.

Quanto à economia política dos sistemas-mundo, serão abordados com maior ênfase os autores Immanuel Wallerstein e Giovanni Arrighi, sem desconsiderar a relevância que outros expoentes como Terence Hopkins e a 
Beverly Silver, de acordo com Martins (20II), têm para essa vertente. No que tange às trocas desiguais, cabe fazer aqui a síntese das ideias e destacar aquele que obteve mais destaque na combinação entre desigualdade e imperialismo, Samir Amin. Essas correntes marcaram época na historicidade do imperialismo, gerando frutos até a atualidade, no fomento de um pensamento independente e autóctone na periferia sobre sua realidade.

\section{Wallerstein e o Sistema-Mundo}

Immanuel Wallerstein destacou-se como um intelectual orgânico, mesclando a atuação acadêmica com a inserção política. Nascido em I930, nos Estados Unidos e estudou por Nova Iorque e rapidamente despertou seu interesse pelo movimento anticolonialista, notadamente o indiano. Veio, infelizmente, a falecer em 20I9. Foi professor de sociologia por várias universidades por todo o mundo, recebendo posteriormente honras e homenagens mundo afora. Nem sua atuação nem seu pensamento se limitaram às fronteiras nacionais. Ao contrário, sua nacionalidade nem sempre é lembrada. Em função de sua vivência e maturidade terem ocorrido pelas décadas de I950 e I960, ou seja, no imediato segundo pós-guerra, seu objeto de estudo foi, enquanto pensador crítico, os processos de descolonização (tanto que seus primeiros livros publicados são sobre os levantes africanos contra as metrópoles). Em outras palavras, ele foi um homem do momento de internacionalização das relações de produção capitalistas para além do continente europeu, do tempo em que o capitalismo se tornou de fato um modo de produção internacional.

O que não foi uma transformação trivial, mas ela ocorreu com base em muito suor, sangue e lágrimas, em um período de ebulição nas franjas do globo. Tanto as revoluções socialistas quanto as insurreições nacionalistas na periferia demonstravam que a relativa estabilidade e prosperidade do pósguerra não se replicava para além do centro. Ademais, o fardo de séculos de colonização revelava que os povos independentes não compactuavam mais com nenhuma ingerência e prezavam por soluções próprias para as questões internas. Assim, emergiu o movimento dos países não alinhados, enfatizando a importância da autonomia do dito Terceiro Mundo na dinâmica internacional. Wallerstein era muito sensível a essas questões, de sorte que direcionou seus estudos, inicialmente, para entender como o todo internacional foi construído e funciona, o que veio a chamar de sistema-mundo. O que lhe buscar a fundo na história as raízes da colonização europeia no mundo, bem como, posteriormente, estudar os desdobramentos pelos espaços da periferia. O que 
lhe valeu a qualificação de um teórico terceiro-mundista, ainda que oriundo da grande potência capitalista e ainda que ele mesmo rejeitasse essa análise compartimentada em três níveis do sistema internacional.

Sua perspectiva holística do sistema-mundo não se restringe a um continente ou a uma região, mas abarca o mundo como um todo contínuo e longevo, retomando suas origens históricas desde os primórdios dos vestígios capitalistas. Ele deixa de lado o nacionalismo metodológico para tratar das categorias teóricas em conjunto, formando um todo particular. O estadunidense torna-se, portanto, fundador e patrona de uma vertente de pensamento que vai agregar grandes expoentes das teorias críticas e vai embasar estudos autóctones sobre a periferia internacional. Em virtude de sua inserção internacional, suas ideias tiveram grande capilaridade, irradiando-se por todo o mundo, formando gerações de internacionalistas e sendo ainda incontornável para qualquer estudo crítico ${ }^{6}$.

O fio condutor de suas concepções pode ser puxado a partir da obra icônica O Sistema-Mundo Moderno, Volume 1 (1974), que pavimenta as bases do sistema-mundo, as quais irão fertilizar diversos estudos sofisticados sobre o tema. Tamanha a ambição da empreitada, leva-o a publicar mais três tomos, em I980, I989 e 20II, respectivamente. Em um contexto de questionamentos à ordem internacional vigente, os estudos críticos vão ao encontro da construção de alternativas teóricas antissistêmicas, que escapassem da defesa do liberalismo pela hegemonia anglo-saxã e do marxismo oficial da III Internacional. O autor faz uma síntese de posições teóricas, que vão desde Braudel e Marx a Weber para embasar sua historicidade do capitalismo e compreender as raízes do sistema atual.

Em sua trajetória, ele retorna às raízes da transição entre feudalismo e capitalismo na Europa, empurrando em três séculos para trás, se comparado com Marx, na agricultura medieval, no longo século XVI, de Braudel, para extrair as origens da modernidade, ressaltando sua tendência inerente à internacionalização, mesmo antes da consolidação do modo de produção. O moderno sistema-mundo gestado na alvorada da modernidade estendese gradativamente até, no século XIX, incorporar todo o planeta. Há uma integração das sociedades em uma rede transnacional de trocas mercantis, a

\footnotetext{
6 Há centros de pensamento que frutificam vastamente na atualidade as interpretações do sistema-mundo. Destacam-se os estudos dos pesquisadores do Fernand Braudel Center da Binghamton University, no estado de Nova York, nos Estados Unidos, de CES (Centro de Estudos Sociais), de Portugual, cujo maior discípulo foi Boaventura de Sousa Santos, e, no Brasil, por exemplo, o Grupo de Pesquisa sobre Economia Político dos Sistemas-Mundo (GPEPSM), da Universidade Federal de Santa Catarina, em Florianópolis, e o Laboratório de Estudos sobre Hegemonia e Contra-hegemonia (LEHC) da Universidade Federal do Rio de Janeiro.
} 
qual vai se desenvolvendo e se aperfeiçoando. Assim, cria-se um sistema social inovador, diferente de outras formas de poder e dominação, que se estende em conexões econômicas, culturais e políticas pelo mundo (Wallerstein I974).

As etapas dessa narrativa englobam o interregno entre I450 e I640, na qual se evidenciam as origens e condicionantes iniciais do sistemamundo, muito atreladas ao cenário europeu; atravessam a modernidade, de I640 a I8I5, em que o sistema se espalhando pelo mundo; até chegar na terceira fase, de I8I5 a I9I7, na qual a expansão demanda do sistema uma readequação à nova realidade. De I9I7 em diante, a atualidade é constituída nas tensões revolucionárias que a consolidação sistêmica provoca. No exercício de ir ao século XV e voltar à atualidade, Wallerstein não se furta de alimentar constantemente a base de suas ideias, adaptando-as às mudanças contemporâneas, a ponto de projetar mesmo o ocaso do sistema-mundo, o qual já teria, inclusive, uma data aproximada7.

O pensamento de Wallerstein, apesar de ter a verve destacada do anticolonialismo, não deixa de flertar com o marxismo ocidental ${ }^{8}$, tradição muito influente aos marxistas de sua época. Em outras palavras, ele rechaçava a ideia bidimensional de estrutura e superestrutura, colocando os dois planos no mesmo patamar e atribuindo às questões relativas à economia, à política, à ideologia, à cultura, à filosofia a mesma importância. Também, como uma marca específica do tempo em que viveu e forjou-se, o do fordismo, do capitalismo industrial, do keynesianismo e do modelo de bem-estar social, direcionava o foco das relações internacionais para o comércio internacional (e desigual). Nessa linha, dentro do sistema-mundo moderno se projeta a economia-mundo, a qual se articula intensamente pelas áreas geográficas via fluxos de capitais e de mercadorias, cuja dinâmica impacta e, ao mesmo tempo, é contaminada pelo sistema interestatal, moldado por questões diversas, como a política e a cultural (Martins 20II).

A interação desses elementos movimenta as transformações e garante o andamento do sistema, que não é, entretanto, linear, mas marcada por ciclos $^{9}$ que se caracterizam e são caracterizados pela liderança do Estado hegemônico. A ênfase em seu objeto sistêmico vincula-se à importância dada para a competição entre os Estados nacionais europeus, a qual, segundo o

7 É o que defende Wallerstein (2009) em estudos e análises mais recentes, apontando para 2050 como um limite e marco de transformação.

8 Losurdo (20I8) explica e situa a tradição dita como ocidental (que não se relaciona com questões geográficas) nas balizas do pensamento marxista.

9 Sob a influência das notórias concepções de Kondratiev, os interregnos se caracterizariam por fases de expansão (fase A) e de crise (fase B), cuja duração de cada qual estaria entre 30 e 60 anos, podendo repetir-se dentro de um ciclo hegemônico. 
autor, não só degenerou em caos político e econômico graças ao comando, ao longo dos últimos 500 anos, de três grandes potências hegemônicas que teriam sido capazes de organizar ou governar o funcionamento hierárquico desse ordenamento (Províncias Unidas, ou o que viria a constituir boa parte da Holanda, Inglaterra e Estados Unidos). A existência de um poder hegemônico seria uma imposição sistêmica para que a unidade não se degringole em um império mundial. Em outras palavras, o intelectual estadunidense parte de uma percepção teórica que flerta com estabilidade hegemônica, do papel do poder hegemônico como fiador do sistema ${ }^{\mathrm{IO}}$.

O poder hegemônico é aquele que se distingue pela proeminência (comando, liderança e influência) nesse espaço, ainda que não possa controlálo plenamente, em função da particularidade do sistema-mundo: ele é incontrolável por um único poder imperial dentro dos marcos do capitalismo. Ainda que o poder hegemônico seja o promotor e garantidor da ordem, ele está imerso em uma dinâmica altamente competitiva entre os Estados, o sistema interestatal, composto por entidades políticas soberanas (Mariutti 2009). Essa engrenagem não é cerrada, podendo haver mutações, entre as variadas camadas da divisão internacional, que configura entre centro, semiperiferia e periferia.

Da síntese eclética proposta por Wallerstein é possível fazer algumas observações pertinentes ao escopo do artigo. O recuo feito na historicidade afeta o rigor teórico do materialismo histórico e dialético de Marx, pois vai além das revoluções Industrial e burguesas (de Estados Unidos e França), o que acaba por misturar conceitos de até nomes semelhantes, mas de conteúdos e especificidade distintos (moldados nos marcos do capitalismo). A interação do sistema-mundo entre economia (economia-mundo) e política (sistema interestatal), por sua vez, é interessante, bem como o foco na competição interestatal como fator de instabilidade e indomável, ou seja, não pode ser controlado por uma única força nas balizas do capitalismo. Ambas as percepções já se aproximam mais de Marx. A economia-mundo fica, no entanto, demasiadamente restrita na esfera da distribuição e circulação do comércio internacional, sem maiores detalhamentos da base produtiva, não se alicerçando nas relações de produção. Assim, tanto as categorias econômicas quanto as políticas por ele utilizadas acabam ganhando contornos idealistas, vulneráveis a pender mais para a abstração do que para a realidade. A divisão internacional do trabalho proposta entre a ramificação tripartite centro, periferia e semiperiferia é meritória, mas carece frequentemente de clareza em

Io Fiori (2004) atribui a Gilpin e Kilndleberger, teóricos realistas e não marxistas, a adesão a essa vertente de pensamento que foi ironicamente chamada de teoria da estabilidade hegemônico dentro dos debates da Economia Política Internacional pelas décadas de i970 e I980. 
suas definições. As mudanças e agitações políticas da década de I960 (como os levantes de maio de I968) são, para ele, um marco de inflexão na trajetória sistêmica, tendo na crise da década seguinte uma de suas consequências. Esse momento o incomoda a ponto de identificar o surgimento de um momento terminal não apenas da hegemonia estadunidense, mas de todo sistemamundo moderno. Seu pensamento heterodoxo o conduz pela demografia, ecologia e aspectos culturais para explicar o desenvolvimento sistêmico, o que o aproxima das perspectivas politicistas.

Nesse amplo enfoque o conceito de imperialismo fica diluído, como acontece dentro da tradição do marxismo ocidental, tornando-se mais um efeito dos mecanismos sistêmicos de reprodução e exploração da desigualdade entre os países, calcada na divisão internacional do trabalho. Em sua abordagem o conceito de hegemonia estaria ainda mais em voga que o de imperialismo, o qual é diluído e relegado a um segundo plano, a ponto de o tema ser tido como o elemento ausente em vários momentos da ampla abordagem sistêmica do autor estadunidense (Brewer I990). Não há, portanto, nenhuma inovação quanto ao imperialismo, mas, sim, a vinculação do conceito às bases economicistas. Atribuídas aos pensadores clássicos do imperialismo, elas seriam insuficientes e superadas e precisariam de atualizações dentro do contexto do pós-guerra (e de ascensão das esquerdas ao poder). Assim, como as teorias da dependência e das trocas desiguais, ele direciona seu foco para a disparidade entre centro e periferia, anelando as bases de seu pensamento nas relações comerciais ou mercadológicas, que se traduzem, dentre outros mecanismos, na divisão internacional do trabalho (Noonan 20I7).

\section{Arrighi e o Sistema-Mundo}

Giovanni Arrighi foi, dentro das teorias do sistema-mundo, o principal seguidor e difusor, contribuindo determinantemente para sua capilaridade mundial e seu aperfeiçoamento. O economista e sociólogo italiano nasceu em I937, nos arredores de Milão, e tornou-se um dos maiores intelectuais contemporâneos. Faleceu em 2009. Fez parte de uma geração do contexto do segundo pós-guerra, de prosperidade e recuperação econômica no centro do capitalismo e de lutas e guerras na periferia. É um contexto de trocas desiguais e de controle monopolístico do comércio. Assim como Wallerstein, o italiano ${ }^{\text {II }}$ sintetizou excertos das reflexões de Marx, Braudel, Weber e também Schumpeter. Na década de ig6o seu interesse foi direcionado ao estudo do

II Callinicos (2009) afirma que Arrighi não pode ser colocado em nenhuma categoria, tendo em vista a complexidade e a temporalidade de seu pensamento. 
desenvolvimento econômico nos países periféricos a partir de uma viagem de trabalho feita à África (Zimbábue e Tanzânia, especificamente). Transitou entre Itália e Estados Unidos tratando das questões candentes do cenário internacional. Do foco na periferia foi alargando-o para o desenvolvimento do capitalismo como um sistema. Assim, voltou-se para a crise da hegemonia estadunidense, as transformações políticas e econômicas decorrentes e chegou a analisar pioneiramente a ascensão da China (e de seu entorno na Ásia) enquanto potência mundial.

Em seus escritos e ideias, parte de Marx, mas buscou romper com o marxismo clássico. Ao contrário de Wallerstein, não entende que se tenha que buscar nos primórdios do feudalismo as raízes da modernidade. Nesse sentido, recua menos no tempo ao mergulhar nas cidades-estados italianas para identificar os germes do capitalismo. Na verificação histórica que empreende o capitalismo como um sistema mundial é datado do século XVI, com origem na acumulação genovesa, e se manteve essencialmente inalterado desde então, sendo relativamente estático quando toca os termos de centro e periferia. Assim, partindo dos conceitos de longa e curta duração de Braudel, mas discordando dele em questões pontuais, sistematiza a história do sistema mundial em ciclos, inspirados nas ondas de Kondratiev, que perpassam desde o longo século XVI até os dias atuais, que seria o longo século XX, o qual é o título de sua obra mais renomada, O Longo Século XX: Dinheiro, poder e as origens de nosso tempo (I994). A linha do tempo é medida pela duração dos processos de acumulação de capital liderados pela potência hegemônica da época.

O sentido de hegemonia é muito caro a Arrighi e, talvez, o principal elemento de dissidência em relação a Wallerstein (quanto à definição conceitual do termo e não quanto à sobreposição da hegemonia ao imperialismo). Tanto que retorna diretamente a Gramsci para aplicá-lo às relações internacionais (Arrighi 2007). O autor ressalta seus dois aspectos fundamentais: liderança (noção etimológica) e dominação (noção derivada). A liderança seria exercida entre Estados quando um ente direciona o sistema para um caminho, cujo movimento é percebido como consonante ao interesse geral, o que reforça sua posição de dominação e, ao mesmo tempo, acirra a competição. Em outras palavras, haveria o consenso e a coerção quando a busca pelo poder não é o único objetivo da ação estatal do ente hegemônico. Em grande medida, as hegemonias mundiais reorganizam o sistema de trocas e de acumulação, fomentando oportunidades de cooperação, ou seja, espraiando também efeitos positivos em âmbito geral ${ }^{12}$. A atuação protagonista da potência hegemônica

I2 Aqui vale para Arrighi a mesma crítica feita por Fiori (2004) a Wallerstein, no sentido de apontarem para uma noção benéfica de hegemonia, como fator de estabilidade. A percepção 
não inviabiliza a concorrência interestatal capitalista, responsável pelas mudanças nos ciclos de acumulação econômica e de dianteira política, que não são esferas coincidentes, mas estão em constante simbiose.

Para Martins (20II), o capitalismo histórico, na visão do italiano, se desenvolveria em duas lógicas distintas e expansivas, capitalista e territorialista, tencionadas por unidade e contradição. Articulam-se em torno da relação imbricada entre economia e política. Assim, a força motriz desse desenvolvimento são as expansões e as reestruturações na economia mundial, encetadas pela liderança de Estados, comunidades ou blocos de agentes governamentais ou empresariais. Por essa tendência pendular, registram-se quatro ciclos sistêmicos de acumulação: um ciclo genovês (embrionário), do século XV ao XVII; um ciclo batavo, do século XVII ao XVIII; um ciclo britânico, do século XIX; e um ciclo estadunidense, do século XX; que traduzem três ondas hegemônicas, a batava e o arranjo de Vestefália, a britânica do livre comércio e a estadunidense da livre iniciativa. Posteriormente, em estudos mais recentes, Arrighi (I996) irá enfatizar somente os três últimos, que são os mais consistentes indubitavelmente, com distinções cintilantes e traços em comum.

Cada etapa é caracterizada pelas mesmas fases, iniciando-se pela expansão material, seguida da expansãofinanceira. Emmeioà sobreacumulação de capital começa a decadência e crise, transição de um poderio para o outro. Verifica-se que os interregnos cíclicos são cada vez mais curtos e as potências hegemônicas, cada vez mais fortes. Arrighi atribui uma importância peculiar, se comparado com Wallerstein, à financeirização. A primazia das finanças, ao contrário do que diriam os autores clássicos do imperialismo, não seria um traço exclusivo do século XIX, mas já estaria presente na relação entre reinos por volta do fim da Idade Média e início da Moderna. A expansão financeira, inclusive, acirraria tanto as contradições capitalistas que seria o ponto de inflexão na dominância estatal de um período, anunciando o ocaso de uma um ciclo. Com fulcro nessa elaboração teórica, Arrighi, ao tatear a crise do modelo fordista na década de I970, é induzido ao erro comum no alvorecer da década de I990 que era apontar para a financeirização do mundo como sinal de declínio da hegemonia americana (outono). Concomitantemente esboça que o Japão viria a suceder os estadunidenses na transição de poder mundial, tendo em vista o padrão de acumulação asiático que poderia vir a suplantar o americano. Por fim, desloca suas atenções para a China em um livro que se tornou referência para o estudo do assunto, Adam Smith em Pequim: origens e

está situada no tempo e no espaço de prosperidade no centro capitalista de I945 a I970, pois a partir da crise da hegemonia estadunidense o comportamento hegemônico mudou por completo, sendo o maior fator de instabilidades sistêmicas. 
fundamentos do século XXI, de 2007.

O imperialismo também não ocupou o centro das preocupações de Arrighi. Ele dedicou, todavia, um estudo a sistematizar as contribuições até então dadas. No livro The Geometry of Imperialism, de I978, o autor toma para si a tarefa de organizar as noções pioneiras, tendo Hobson como paradigma maior, e compará-las com as formulações existentes, no que chamará de segundo ciclo do imperialismo, das décadas de i950 e I960. Imperialismo, para Arrighi (I983), não seria o panorama de anarquia nas relações interestatais que emerge da competição entre Estados centrais por territórios, mas a ordem hierárquica de Estados e a consequente estrutura de dominação específica, que caracteriza a economia-mundo capitalista desde a Segunda Guerra Mundial. Fiel às suas concepções teóricas, não foge à historicidade e aos ciclos hegemônicos. Assim, haveria diversas fases de imperialismo em um ciclo hegemônico. Ele tenta ilustrar essas periodizações por figuras geométricas, traçando identidades e disparidades. Em outras palavras, o imperialismo ainda estava eclipsado por outras questões prioritárias e muito atrelado à sua vertente econômica.

A despeito de diferenças significativas, Arrighi mais se aproxima do que se afasta de Wallerstein (principalmente no tocante ao conceito de imperialismo), e compartilha tanto dos limites epistemológicos ${ }^{13}$ quanto do grande mérito das teorias do sistema-mundo. Elas chamam a atenção para a análise da desigualdade das relações econômicas internacionais por meio de uma visão sistêmica, holística e histórica. Sua amplitude e heterodoxia permitem o diálogo profícuo como outras perspectivas, com as de autores da dependência, como Frank e Dos Santos, mais especificamente, e, sobretudo, com o ecletismo de Amin (e o comércio internacional desigual).

\section{Amin e as Trocas Desiguais}

Samir Amin foi um economista político e um dos maiores expoentes do terceiro-mundismo ${ }^{\mathrm{I} 4}$ e do anticolonialismo. Nasceu em Cairo, em I93I, no

I3 Nesse sentindo, cabe aqui elencar os principais pontos questionáveis das teorias do sistemamundo, que se direcionam para seu viés funcionalista, o seu descolamento com as premissas marxianas e a noção estendida de historicidade do capitalismo. Para mais ver Gerstenberg (2010).

I4 O conceito é discutível, podendo ter uma abordagem ampla, envolvendo todos aqueles que discutem o subdesenvolvimento nas regiões periféricas (teóricos da dependência, do sistema-mundo e das trocas desiguais), ou um enfoque restrito, tocando apenas os intelectuais radicados nos grandes centros que direcionavam sua atenção à periferia, como aqueles das trocas desiguais. A maior parte da literatura, de origem anglo-saxônica, tende priorizar a 
Egito, mas estudou e trabalhou na França e em muitos países francófonos da África, como o Senegal, Mali e Argélia, em instituições políticas, econômicas (de desenvolvimento) e acadêmicas. Faleceu em 20I8. Ele não foi um sucessor direto das teorias do sistema-mundo, na linhagem de Wallerstein e Arrighi, mas está no mesmo patamar de importância e relevância exercida nos estudos marxistas internacionalistas. Sua concepção, também eclética, tangencia a compreensão teórica do sistema-mundo, podendo ser inscrita nessa tradição, mas também com outras vertentes, com as da dependência ${ }^{15}$, até mais estreitamente como ocorre com o comércio internacional desigual. Comunista e antifascista desde jovem, na França, ele filiou-se ao partido comunista francês e foi gradativamente afastando-se do modelo soviético e aproximandose do maoísmo. Viveu de perto e engajou-se no movimento dos países não alinhados e prezou ativamente pela independência e desenvolvimento dos países periféricos.

Imerso em seu tempo e com as lentes voltadas para a periferia mundial, sua preocupação central era o desenvolvimento econômico em nível global. De imediato, assim com as vertentes cepalinas ${ }^{16}$, ele identificou as lacunas das teorias da modernização do centro, voltadas a um etapismo na escala do progresso econômico. Rapidamente, foi além, entendendo o subdesenvolvimento como a face reversa do desenvolvimento. Com base na síntese entre lei do valor (e suas categorias econômicos) e materialismo histórico (com ênfase na luta de classes), ele formulava uma lei do valor mundial para explicar que os países periféricos teriam suas possibilidades de crescimento restritas e bloqueadas pelas economias centrais, que se utilizavam

perspectiva mais genérica. Para mais ver Callinicos (2009), Brewer (I990), Barone (I985) e Carnoy (I994).

I5 Amin exalta aspectos da dinâmica expropriatória do centro em relação à periferia, citando a superexploração da força de trabalho, o que permitiria inscrevê-lo nas teorias marxistas da dependência (Brewer I990 e Côrrea 20I2).

I6 Teses cepalinas são aquelas que surgiram em torno da CEPAL (Comissão Econômica para a América Latina e Caribe), um órgão criado no âmbito das Nações Unidas (ONU), vinculado ao Conselho de Desenvolvimento Econômico e Social (ECOSOC), focadas na crítica à perspectiva universalista do desenvolvimento irradiada pelos cânones tradicionais (Lewis, Nurkse, Rostow e Rosenstein-Rodan) do centro sobre a questão. Nessas visões, em clara contraposição às teses ricardianas de especialização dos países via vantagens comparativas, explica-se o atraso dos países periféricos a partir do conceito de desenvolvimento desigual, enfatizando as assimetrias periféricas, de localidades primário-exportadoras em relação ao centro, industrializado, o que levaria à permanente deterioração dos meios de troca, ao desequilíbrio do balanço de pagamentos e ao desemprego. A solução apresentada seria a substituição de importações pela constante ação do Estado como fomentador do desenvolvimento nacional, estimulando indústrias locais, o mercado interno, a distribuição de renda, a incorporação de tecnologia e a modificação progressiva da pauta exportadora. 
do mecanismo da superexploração da mão de obra periférica. O materialismo histórico teria, inclusive, premência sobre a lei do valor, modulando-a e movimentando as transformações mundiais, ou seja, atribuindo uma importância central aos fenômenos políticos. Portanto, o desenvolvimento capitalista precisaria ser analisado em sua totalidade, na esfera global, mas as estratégias de autonomia e crescimento dos países subdesenvolvidos deveriam ser apartadas desse todo, escapando dos limites estruturais impostos. Ele combina a ênfase na assimetria das relações entre centro e periferia com a análise de classes, explanando a dificuldade dos líderes do Terceiro Mundo em resistir ao imperialismo, aproximando-se definitivamente de Lênin (Noonan 20I7).

Partindo de ideias de Marx, Braudel e Polanyi, o autor mesclou sua visão com as interpretações mais destacadas no pós-guerra sobre capitalismo, desenvolvimento e periferia, como a do capital monopolista de Baran e Sweezy, na corrente que ficaria conhecida como do capital monopolista ${ }^{17}$. O que significa reconhecer a tendência do capitalismo à superacumulação e os consequentes problemas com a absorção do excedente. A estagnação seria a regra nesse cenário, a qual somente poderia ser combatida com a produção centrada no Estado. Assim, o capitalismo tardio do pós-guerra reuniu condições muito peculiares e, por isso, foi exceção, e, com a crise dos anos I970 e I980, o foco saiu do Estado para a financeirização como elemento propulsor para fora da estagnação. Em sua periodização, de final do século XIX até I97I foi a era do capital monopolista tradicional e dali em diante emerge um capitalismo oligopolista financeiro e impacta nas relações internacionais até hoje.

Diferentemente de Wallerstein e Arrighi, Amin dedica nominalmente, até, muitos escritos a pensar o imperialismo. Em virtude disso, veio a público, em I97I, a primeira edição de Imperialismo e Comércio Internacional (a troca desigual ${ }^{18}$. O rumo desse viés direciona-se pela desigualdade das relações

I7 A escola do capital monopolista, formada basicamente por seus fundadores, Paul Baran e de Paul Sweezy, a despeito de contribuições esparsas e indiretas, foi uma primeira manifestação da continuação das reflexões marxistas sobre imperialismo e, concomitantemente, da atualização das ideias dos pioneiros, no pós-Segunda Guerra Mundial, inserindo o elemento da periferia. De publicações acadêmicas a inserções conjunturais no periódico Monthly Review, os dois intelectuais divulgaram suas interpretações pelo mundo. Por todo o engajamento político que a revista particularizou, ela conseguiu reunir um corpo de intelectuais, que ficou conhecido como grupo do Monthly Review, o qual foi marcado por uma visão muito peculiar nesse debate fordista e que, posteriormente, foi se renovando ao longo dos anos.

I8 A obra reuniu artigos especializados dos principais expoentes dessa leitura, como Arghiri Emmanuel, Samir Amin, Charles Bettelheim e Christian Palloix. Os motivos das evidentes assimetrias eram o cerne das divergências entre eles, residindo no valor da força de trabalho (salários), para Emmanuel; na luta de classes, materializada na superexploração do trabalho 
capitalistas, como ênfase às trocas comerciais. Pressupõe-se que o valor sai da periferia para o centro, sendo por ele apropriado, bem como todas as decorrências disso, como a migração seletiva de mão de obra. E os monopólios se intensificam, com o controle em várias searas, desde tecnologia, finanças e recursos naturais. Nos países subdesenvolvidos as mercadorias produzidas eram trocadas por uma quantidade menor de valor do que aquele realmente nelas contido, enquanto que nos desenvolvidos o oposto ocorreria. A dinâmica da acumulação não permite, contudo, que esse universo se divida entre entes homogêneos, ao contrário, tendo em vista sua tendência ao desenvolvimento assimétrico, fomenta formações socioeconômicas díspares, contendo diferentes manifestações do modo de produção. A clivagem principal é aquela que ocorre em duas categorias: centro e periferia. No centro o crescimento é autônomo, enquanto na periferia é bloqueado, em função da competição das grandes potências. A especialização desigual decorrente dessa dinâmica é determinada pelos custos absolutos de produção (e não pelas vantagens comparativas), sendo que estes dependem da produtividade e dos salários. Logo, aquelas nações que se industrializaram mais cedo levam uma vantagem imensa em relação às retardatárias. Assim, o desenvolvimento desigual oriundo desse panorama é ancorado na esfera da circulação, traduzido nas assimétricas relações de troca.

As trocas desiguais estão inseridas nesse âmbito maior, que vai se modulando ao sabor das transformações, mas tem no imperialismo e no desenvolvimento desigual suas raízes. Sobre o assunto Amin escreveu trabalhos sobre a crise do imperialismo e desenvolvimento desigual, ainda nos anos I970. Para ele, o imperialismo organiza, sob a dominação dos capitais monopolistas, uma imensa pirâmide de formas de exploração do trabalho, em cujos diferentes níveis participam todas as burguesias e as classes exploradas do sistema mundial, estrategicamente situadas no campo do capitalismo. Ressalta a exploração, em suas diversas formas, dos proletários tanto no centro quanto na periferia, todos integrados ao sistema imperialista. Em função disso, reside a necessidade de unificação para o levante rumo ao socialismo. Parafraseando Lênin, afirma que não apenas os proletários do mundo, mas também os povos oprimidos deveriam se unir (Amin i977a).

Em seu ambicioso e longevo (escreve sobre a temática desde a década de I950) esforço, busca explicar a expansão do capitalismo pelo mundo e, simultaneamente, o impacto desse espraiamento nas diversas regiões, como uma síntese das principais premissas marxistas em curso à

na periferia pelo centro, para Amin; na composição orgânica do capital e nas disparidades regionais, para Bettelheim; e na taxa de exploração contida na essência da economia política, para Palloix. 
época. Posteriormente, com o tempo, ele vai apurando sua compreensão ${ }^{\mathrm{I}}$. Assim, é com base em sua lei do valor mundial que ele retira o conceito de imperialismo. Relacionando-o diretamente com o modo de produção capitalista, ele seria o elemento aglutinador entre os mecanismos e leis para a reprodução do capital; as alianças sociais, nacionais e internacionais que os sustenta; e as estratégias políticas empregadas por essas alianças. Acompanhando o vínculo ao capitalismo, ele busca as razões históricas dessa dinâmica no eurocentrismo, que o remete para a análise das colonizações na Idade Moderna. O imperialismo acompanhando as transformações do capital monopolista, no século XIX, consolidou a segregação em um esquema de escala mundial entre centro e periferia.

A combinação das questões econômicas, ainda muito atrelada ao conceito de imperialismo, com as políticas, direcionando a lente para a luta de classes em escala mundial é sua grande contribuição. Seu ponto de partida teórico ampliado, o sistema-mundo, não o impede de analisar as particularidades nacionais, sobretudo na periferia (de África e Ásia, mais detidamente) nas quais residiriam as fagulhas de possíveis rupturas com a dinâmica sistêmica. A combatividade e inquietude fizeram com que Amin tenha sido um dos poucos teóricos a resistir no tempo, atravessando gerações, como um dos principais críticos do capitalismo.

\section{Considerações Finais}

Por mais efêmero que pareça, tendo durado aproximadamente um quarto de século, o debate fordista não pode ser olvidado, uma vez que caracteriza importante interregno de transição para os horizontes que se apresentaram no contexto posterior. Conforme se pode constatar, a análise do imperialismo foi alargada e, concomitantemente, diluída, em argumentos que a englobaram no relevo de questões mais afins às relações desiguais entre centro e periferia no desenvolvimento mundial das relações capitalistas. O que importa apontar é que, não obstante as substanciais modificações geopolíticas carreadas, no tocante à teoria não houve um rompimento pleno com os pioneiros, configurando o interregno fordista muito mais uma complementação às primeiras ideias marxistas de imperialismo (uma vinculação direta entre imperialismo e sua base econômica), mas com novidades cruciais. Alicerçados em bases primárias, os autores desse momento não reavaliaram em si o fenômeno do imperialismo, mas procuraram entendê-lo por perspectivas mais abrangentes que consideravam necessária

I9 Amin 2005 e 2006. 
a ênfase em mecanismos que envolviam, em maior ou menor medida, o comércio internacional ou a esfera da circulação, o excedente econômico, a transferência de valor, o sistema mundial e as trocas desiguais.

O ponto em comum das duas interpretações em tela (sistemamundo e trocas desiguais) é tomar o capitalismo como um sistema mundial, de tendência descompassada entre as partes envolvidas. Ao contrário do que pensavam os pioneiros, a expansão do capitalismo não o levou à sua reversão, devido suas contradições inerentes, mas, sim, à sua consolidação enquanto modo de produção mundial. Alargou-se o que deveria ser fechado. O capitalismo logrou construir um mercado mundial, que as relações de produção se expressam, todavia, cada vez mais distorcidas, alimentando uma dinâmica extremamente incongruente. $\mathrm{O}$ atraso dos países dependentes precisa ser tomado seriamente em análise, inserindo-o em seu espaço, no sistema internacional. É a falência do capitalismo na função de gerar ampla prosperidade e desenvolvimento que acarreta o a imperiosidade de mudanças. A unidade de análise não é a formação social nacional e a correlação de classes, mas o sistema mundial, como um conjunto, tendo áreas geográficas distintas, e sendo partes os Estados e as classes desse todo.

Ainda que o ecletismo dos autores não nos permita colocá-los em um mesmo esquadro, e os deixa vulneráveis a críticas em vários aspectos, rever as três contribuições é fundamental para o aprofundamento dos estudos sobre imperialismo. O que os unifica é que eles pensam em um contexto no qual o capitalismo chega às franjas do globo, ou seja, a periferia emerge, com o esgarçamento dos tecidos sociais pela introdução das relações de produção capitalistas, para além da Europa e de pontos no hemisfério norte. Logo, o momento do modo de desenvolvimento do capitalismo, fordismo, impacta diretamente na formulação teórica e política deles. Cada qual à sua maneira, Wallerstein como a noção de sistema, Arrighi com a historicidade pela hegemonia e Amin pela ênfase à desigualdade e à luta de classes, eles fortalecem o debate, trazendo interpretações sobre as assimetrias das relações centro e periferia que servem como fermento das concepções críticas, projetando-se em uma carreira longeva e militante de principais referências para a crítica do capitalismo (e da globalização financeira) até hoje.

\section{REFERÊNCIAS}

Amaral, Marisa Silva. 20I2. Teorias do Imperialismo e da Dependência: a atualização necessária ante a financeirização do capitalismo. Tese (Faculdade de Economia)- Universidade de São Paulo, São Paulo. 
Amin, Samir. I97I. "El comercio internacional y los flujos internacionales de capitales" In: Amin, Samir, Palloix, Christian, Emmanuel, Arghiri e Bettelheim, Charles. Imperialismo y comercio internacional (el intercambio desigual). Buenos Aires: Cuadernos de Pasado y Presente 24, 67-99.

Amin, Samir. I977a. "Uma crise estrutural”. In: AMIN, Samir. A Crise do Imperialismo. Rio de Janeiro: Edições Graal, 5-44.

Amin, Samir. I977b. Imperialism and Unequal Development. New York: Monthly Review Press.

Amin, Samir. 2005. “Imperialismo, passado e presente". Tempo I8: 77-I23. Rio de Janeiro.

Amin, Samir. 2006. "Geopolítica do capitalismo contemporâneo". Novos Rumos 2I (45): 3-30. UNESP-Marília.

Anderson, Perry. 2004. Considerações sobre o marxismo ocidental: nas trilhas do materialismo histórico. São Paulo: Boitempo, 2004.

Arrighi, Giovanni. I983. The Geometry of Imperialism. The limits of Hobson's paradigm. London: Verso.

Arrighi, Giovanni. 1996. O Longo Século XX. Dinheiro, Poder e as Origens do Nosso Tempo. Rio de Janeiro: Editora Contraponto.

Arrighi, Giovanni. 2003. "Lineages of Empire”. In: Balakrishnan, Gopal (ed.). Debating Empire. London: Verso, 29-42.

Arrighi, Giovanni. 2004. "As escalas da turbulência global". Margem Esquerda. Ensaios marxistas (5): 58-63. São Paulo: Boitempo.

Arrighi, Giovanni. 2007. "As três hegemonias do capitalismo histórico". In: Gill, Stephen (org). Gramsci: materialismo histórico e relações internacionais. Rio de Janeiro: Editora UFRJ, 227-274.

Barone, Charles. I985. Marxist Thought on Imperialism. Survey and Critique. New York: M.E. Sharpe, Inc..

Bellamy Foster, John. 20II. "Samir Amin at 80: An Introduction and a Tribute”. Monthly Review 5 (63) Outubro. Acesso em 20 maio de 2020. https://monthlyreview.org/20I1/Io/or/samir-amin-at-8o-an-introduction-and-tribute/.

Bonefeld, Werner e Holloway, John. I991. "Introduction: Post-Fordism and social form”. In: Bonefeld, Werner e Holloway, John. Post-Fordism Q social form. A Marxist debate on the Post-Fordist State. London: Macmillan Academic and Professional LTD, I-7.

Brewer, Anthony. I990. Marxist theories of imperialism: a critical survey. 2nd. ed. London: Routledge. 
Callinicos, Alex. 2009. Imperialism and Global Political Economy. Cambridge; Malden: Polity.

Carnoy, Martin. I994. Estado e teoria política. Campinas-SP: Editora Papirus.

Cox, Robert. 2007. "Gramsci, hegemonia e relações internacionais: um ensaio sobre o método". In: Gill, Stephen. Gramsci, Materialismo Histórico e Relações Internacionais. Rio de Janeiro: Editora UFRJ, IOI-I24.

Fiori, José Luis. 2004. "Formação, Expansão e Limites do Poder Global”. IN: FIORI, José Luis. O Poder Americano. Petrópolis: Editora Vozes, II-66.

Gerstenberg, Heide. 20I0. "The Historical Constitution of the political forms of capitalism”. Antipode. A Radical Journal of Geography 43 (I): 60-86. New York: Wiley Blackwell.

Hirsch, Joachim. 20ıo. Teoria Materialista do Estado: processos de transformação do sistema capitalista de Estados. Rio de Janeiro: Editora Revan.

Jessop, Bob. I99I. "Regulation theory, post Fordism and the State. More than a reply to Werner Bonefeld". In: Bonefeld, Werner e Holloway, John. Post-Fordism \& social form. A Marxist debate on the Post-Fordist State. London: Macmillan Academic and Professional LTD, 69-9I.

Losurdo, Domenico. O marxismo ocidental: como nasceu, como cresceu e como pode renascer. São Paulo: Boitempo, 2018.

Mariutti, Eduardo. 2009. Colonialismo, imperialismo e o desenvolvimento econômico europeu. São Paulo: Hucitec.

Martins, Carlos Eduardo. 20II. Globalização, dependência e neoliberalismo na América Latina. São Paulo: Boitempo.

Nogueira, João Pontes e Messari, Nizar. 2005. Teoria das Relações Internacionais. Correntes e debates. Rio de Janeiro: Elsevier.

Noonan, Murray. 20I7. Marxist Theories of Imperialism. A History. London/ New York: IB Tauris \& Co.

Osorio, Luiz Felipe Brandão. 20I8. Imperialismo, Estado e Relações Internacionais. São Paulo: Ideias \& Letras.

Wallerstein, Immanuel. I974. The Modern World System. Capitalist Agriculture and the Origins of the European World-Economy in the Sixteenth Century. Londres: Academic Press.

Wallerstein, Immanuel. 1985. O Capitalismo Histórico. São Paulo: Brasiliense.

Wallerstein, Immanuel. 2009. "Mudando a geopolítica do sistema-mundo: I945-2025”. In: Martins, Carlos Eduardo e Valência, Adrián Sotelo. A América Latina e os Desafios da Globalização. Ensaios em Homenagem a Ruy Mauro Marini. Rio de Janeiro: Editora PUC, 52-78. 


\section{RESUMO}

O imperialismo ganha nova roupagem após a Segunda Guerra Mundial. Em um panorama de expansão das relações de produção, o capitalismo torna-se, de fato, um modo de produção mundial, com bases no fordismo. Nessa dinâmica, novos elementos são incorporados à análise das relações internacionais, como a periferia, as trocas desiguais, a transferência de valor e o sistema mundial, os quais acabam não apenas eclipsando o imperialismo, mas também lhe dando outros contornos. Nessa toada, cabe aqui investigar três autores influentes, como Wallerstein, Arrighi e Amin, demonstrando seu lugar e seus limites no debate central das relações internacionais. Com o tempo, os três, pelo vigor das ideias e o engajamento político, tornaram-se autores incontornáveis para a crítica do momento do capitalismo em que estamos inseridos, ainda que seja para refutá-los. Estudá-lo significa desatar mais um importante nó na tarefa de investigação do imperialismo, conceito essencial para a compreensão da realidade.

\section{PALAVRAS-CHAVE}

Imperialismo; Capitalismo; Relações Internacionais.

Recebido em 13 de agosto de 2019 Aprovado em 31 de outubro de 2020 